\title{
Editorial
}

\section{Direito à cidade de migrantes e refugiados}

Roberto Marinucci*

Em 2015, no meio da assim chamada "crise dos refugiados"1 , na Europa, milhares de pessoas em diferentes países manifestaram a própria disponibilidade para dar abrigo a pessoas em fuga de violências e conflitos. Uma atitude, em muitos casos, em clara contraposição às políticas migratórias restritivas e seletivas dos próprios governos ${ }^{2}$. Esse acontecimento nos leva a indagar sobre a possibilidade da criação de espaços sociogeográficos "locais" de hospitalidade inclusiva e solidária na contramão das legislações nacionais ou regionais. É esse o foco do Dossiê da REMHU n. 52, que aborda o tema a partir dos "espaços urbanos".

Pode-se postular, de fato, a contraposição entre um modelo "nacional" de gestão das migrações, tendencialmente focado na seleção, categorização e concentração dos recém-chegados, e uma abordagem "local" que, sob determinadas condições, pode promover dinâmicas interacionais e inclusivas (cf. Furri), fixando o olhar no "princípio da residência" - nas palavras de

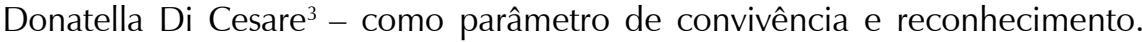
Nas territorialidades locais, as assépticas categorias coletivas e os frios números dos relatórios se transformam em pessoas concretas e únicas.

As assim chamadas "cidades santuário" ou "cidades refúgio" são um exemplo dessa tentativa de produção de redes urbanas de solidariedade focadas - somo sublinha Emanuele Sgroi - na perspectiva das cidades "che si

Editor chefe da REMHU, Centro Scalabriniano de Estudos Migratórios. Brasília, DF, Brasil.

1 Cf. GOMARASCA, Paolo. Direito de excluir ou dever de acolher? A migração forçada como uma questão ética; PADILLA, Beatriz, GOLDBERG, Alejandro. Dimensiones reales y simbólicas de la "crisis de refugiados" en Europa: un análisis crítico desde Portugal. REMHU, Revista Interdisciplinar da Mobilidade Humana, v. 25, n. 51, dez. 2017, p. 11-27.

2 Veja-se, por exemplo, os assim chamados "corredores humanitários" promovidos por segmentos da sociedade civil na Itália e na França (cf. MOROZZO DELLA ROCCA, Paolo. Os assim chamados "corredores humanitários" e o possível papel da sociedade civil nas políticas de refúgio e migração regular. REMHU, Revista Interdisciplinar da Mobilidade Humana, v. 25, n. 51, dez. 2017, p. 47-57).

3 DI CESARE, Donatella. Stranieri residenti. Una filosofia della migrazione. 
tengono per mano" ${ }^{\prime 4}$, gerando um conjunto de políticas locais interdependentes e participativas com vistas ao reconhecimento do "direito à cidade" de todos os sujeitos residentes, independentemente de sua origem e nacionalidade. O direito à cidade ${ }^{5}$ é interpretado não apenas como direito de usufruir dos vários serviços localmente oferecidos, mas também como direito à produção de territorialidades urbanas moldadas a partir dos próprios referenciais étnicos, culturais e axiológicos (cf. Magalhães, Bógus, Baeninger; Heil; Ramírez Sarabia).

É importante sublinhar, como evidenciam vários autores do Dossiê, que a geração de espaços urbanos solidários e inclusivos não é automática ou inevitável. A proximidade pode gerar empatia, mas também rejeição (cf. Briata, Bricocoli, Bovo). Muito depende do tipo de políticas públicas que são elaboradas e implementadas (cf. Marzorati, Marconi). O espaço urbano, nesse sentido, se torna palco de disputas ${ }^{6}$ entre tendências segregativas (cf. Mera) e interacionais, esforços para a criação de guetos - voluntários ou involuntários e lutas pela cidadania enquanto reconhecimento do direito de produzir e fruir das territorialidades urbanas (cf. Vaccotti; Stopani, Pampuro).

Além do âmbito político, muitos outros fatores e atores sociais estão envolvidos e incidem nessas disputas, que dificilmente podem ser abordadas de forma abstrata e descontextualizada. Nesse sentido, é mister levar em conta a tipologia e o tamanho dos centros urbanos, as características socioculturais de seus moradores, os fatores históricos, as conjunturas econômicas, os bens materiais e imateriais acessíveis aos recém chegados e inclusive elementos que transcendem as fronteiras urbanas, como legislações nacionais, instrumentos internacionais de proteção e, até, redes transnacionais.

Merece um destaque o papel exercido pela ação protagônica dos próprios migrantes e refugiados: tendo como pano de fundo os enfoques teóricos "autonomistas"7 e dos "atos de cidadania"8, vários autores do Dossiê interpretam o espaço urbano como um lugar de "negociação" (cf. Césaro, Zanini; Briata, Bricocoli, Bovo; Heil; Vaccotti; Ramírez Sarabia), em que migrantes e refugiados, apesar de sua condição subalterna, recorrem cotidianamente a recursos materiais e imateriais disponíveis para alcançar o direito a uma "cidadania migrante" (cf. Stopani, Pampuro) que Ihes permita "viver" com dignidade, "conviver" de forma simétrica e "reviver" espaços de familiaridade mediante a ressignificação das novas territorialidades urbanas.

\footnotetext{
SGROI, Emanuele. Introduzione. II Mediterraneo. Le città che si tengono per mano, p. 32.

Cf. LEFEBVRE, Henri. Direito à cidade.

Cf. HARVEY, David. Cidades Rebeldes: Do direito à cidade à revolução urbana.

Cf. MEZZADRA, Sandro. The gaze of Autonomy: Capitalism, Migration and Social Struggles. In SQUIRE, Vicki (ed.). The Contested Politics of Mobility. Borderzones and Irregularity. London: Routledge, 2011, p. 121-142.

8 Cf. ISIN, Engin, NIELSEN, Greg (eds.). Acts of citizenship. London: Zed Books, 2008.
} 
O Dossiê aborda essas temáticas de forma interdisciplinar, analisando diferentes temas: Filippo Furri reflete sobre as "cidades santuários" na Itália, que constituem tentativas de moldar a relação com a alteridade em termos inclusivos e solidários, promovendo dinâmicas de encontro que por vezes se apresentam em contraposição às políticas governamentais. As lutas pela moradia e, de forma mais ampla, pelo reconhecimento da condição de sujeitos de direitos são abordadas por Luciana Vaccotti em relação a peruanos em Buenos Aires, e Antonio Stopani e Marta Pampuro em relação a imigrantes africanos na cidade de Turim, na Itália. Esses movimentos de reivindicação, formais ou informais, contribuem para desnaturalizar os processos discriminatórios e postular dinâmicas cidadãs.

Vários artigos focalizam os complexos processos de produção, negociação e ressignificação de espaços urbanos: Luís Felipe Aires Magalhães, Lúcia Maria Machado Bógus e Rosana Baeninger analisam a transformação da paisagem urbana pela produção de territorialidades por parte das comunidades haitianas e bolivianas na cidade de São Paulo, com destaque para a presença e a ação das mulheres; o artigo de Filipe Seefeldt de Césaro e Maria Catarina Chitolina Zanini verte sobre as estratégias de produção de espaço urbano e a inserção no comércio de rua de migrantes senegaleses em Santa Maria, RS; Tilmann Heil também se debruça sobre a imigração senegalesa, examinando sua infraestrutura de recepção na cidade do Rio de Janeiro e a rede transnacional que a sustenta; por sua vez, Santiago Ramírez Sarabia dedica sua reflexão ao tema dos espaços "afrourbanos" como lugares de produção e reprodução das tradições culturais e espirituais de afrocolombianos desterritorializados.

A questão da governança da diversidade cultural no âmbito urbano é o foco do artigo de Roberta Marzorati e Giovanna Marconi que debatem sobre os avanços e os limites da elaboração e implementação da Ley de interculturalidad na Cidade do México. Já Paola Briata, Massimo Bricocoli e Martina Bovo estudam o processo cotidiano de negociação do espaço público na interação de pessoas em um filobus (autocarro elétrico) de Milão, na Itália: as paisagens interacionais descritas pelos observadores podem ser consideradas um "laboratório" para a convivência e a contrução de políticas de cohabitação urbana. Por fim, Gabriela Mera examina a distribuição espacial de paraguaios, bolivianos e peruanos em Buenos Aires, chamando a atenção sobre as diferentes estratégias de assentamento e, ao mesmo tempo, sobre a vulnerabilização dos migrantes.

Na seção Artigos, Emanuela Bini aprofunda os desafios da presença e as boas práticas de acolhida de famílias migrantes que possuem filhos "portadores de deficiência", um tema pouco aprofundado nas pesquisas acadêmicas e que merece destaque; Jesselyn Nayara Tashima e Cláudio Vaz Torres, por sua vez, aprofundam a percepção da aculturação de decasséguis e sojourners brasileiros no Japão sob o olhar da Psicologia Transcultural, trazendo contribuições sobre 
as variáveis que mais incidem no processo; encerra a seção o artigo de Raúl Delgado Wise e Selene Gaspar Olvera sobre as remessas de migrantes a partir da experiência mexicana: entre outros aspectos, os autores sublinham que, de fato, ocorre uma "transferencia de los costos educativos y de reproducción social de la fuerza de trabajo migrante del país de origen al país de destino", o que, junto com outros fatores, desmascara o "carácter restringido y mistificador del discurso dominante en torno a las remesas" (p. 261).

Na seção Relatos e reflexões, Milva Caro apresenta a própria experiência de atuação na Pastoral intercultural entre jovens na Alemanha. A apresentação do livro "Brasileiros nos Estados Unidos - Meio século (re)fazendo a América (1960-2010)" de Álvaro Eduardo de Castro Lima e Alanni de Lacerda Barbosa de Castro encerra o número da revista.

Desejamos a todos e todas uma boa leitura!

\section{Bibliografia}

DI CESARE, Donatella. Stranieri residenti. Una filosofia della migrazione. Torino: Bollati Boringhieri, 2017.

GOMARASCA, Paolo. Direito de excluir ou dever de acolher? A migração forçada como uma questão ética. REMHU, Revista Interdisciplinar da Mobilidade Humana, v. 25, n. 50, ago 2017,

HARVEY, David. Cidades Rebeldes: Do direito à cidade à revolução urbana. São Paulo: Martins Fontes, 2014.

LEFEBVRE, Henri. Direito à cidade. São Paulo: Centauro, 2011.

SEMPREBON, Michela; BONIZZONI, Paola; MARZORATI, Roberta (a cura di). Non solo grandi città. L'immigazione nei piccoli comuni italiani. Mondi Migranti, n. 1, 2017.

SGROI, Emanuele. Introduzione. II Mediterraneo. Le città che si tengono per mano. In ANGELINI, Aurelio (org.). Mediterraneo. Città, culture, ambiente, governance, migranti. Milano: Franco Angeli, 2007. 